\title{
Desequilíbrio nutricional e composição do leite em uma unidade de produção situada na bacia leiteira central da Argentina
}

\author{
Nutritional unbalance and milk composition in a production \\ unit located in the central dairy belt of Argentina
}

Victoria Noel Vázquez Fernandez ${ }^{1} \&$ Maira Balbinotti Zanela ${ }^{2}$

\begin{abstract}
RESUMO
A composição do leite é um fator de suma importância, seja por seu melhor aproveitamento industrial, seja pelo pagamento dado ao produtor. O teor de nutrientes do leite, principalmente gordura e proteína, é resultado do somatório de vários fatores relacionados à produção. O objetivo desse trabalho é relatar uma situação de desequilíbrio nutricional, ocorrida em uma propriedade da Bacia Leiteira Central da Argentina, e as conseqüentes variações na composição do leite. A dieta das vacas em lactação era composta por alfafa ad libitum sob pastoreio direto, grãos de milho e/ou sorgo, silagem de milho ou sorgo, feno de setária ou alfafa e permeado de lactose. Foi observada a ocorrência nos animais de: claudicação, pododermatites, diarréia profusa e alimentos não digeridos nas fezes, diminuição dos sólidos totais e aumento do teor de nitrogênio uréico no leite. Os sintomas indicaram acidose. Foram realizadas medidas de correção da dieta, com aumento do aporte de fibra efetiva e redução do permeado de lactose. Houve diminuição da sintomatologia observada, com redução do nitrogênio uréico e aumento do teor de sólidos totais do leite.
\end{abstract}

Descritores: acidose ruminal, NUL, permeado de lactose, PDR, sólidos totais do leite.

\section{ABSTRACT}

The composition of milk is a factor of the utmost importance, be it for its best industrial usage, be it for the payment of it to the producer. The nutrient content of milk, mainly fat and protein, is due to the sum of several factors related to production. The objective of this work is report a situation of nutritional unbalance, occurred in a property in the Central Dairy Belt of Argentina and the consequent variations in the composition of milk. The diet of cows in lactation was composed of alfalfa $a d$ libitum under direct grazing, corn and/or sorghum grains, corn and/or sorghum silage, setaria or alfalfa hay and lactose permeate. It was observed in the animals the occurrence of: limping, pododermatitis, profuse diarrhea and non-digested feed in the feces, decrease of total solids and increase of uric nitrogen content in the milk. Symptoms indicated acidosis. Corrective measures in the diet were done, with an increase of effective fiber contribution and reduction of lactose permeate. There was a decrease in the symptomatology observed, with a decrease of uric nitrogen and an increase in the content of milk total solids.

Key words: ruminal acidosis, MUN, lactose permeate, RDP, milk total solids. 


\section{INTRODUÇÃO}

A composição do leite é um fator de suma importância à indústria, seja por seu melhor aproveitamento industrial, seja pelo pagamento dado ao produtor. O teor de nutrientes do leite, principalmente gordura e proteína, é resultado do somatório de vários fatores relacionados à produção, que devem ser compreendidos a fim de melhorar a qualidade do leite produzido.

A proteína é, dentre os nutrientes do leite, aquele que tem o maior valor de mercado, e os teores de suas frações (nitrogênio uréico, proteína verdadeira, etc.) são usados como marcadores do balanço nutricional da dieta. Valores alterados podem indicar um desequilíbrio nutricional, resultando em reflexos negativos na produção de derivados lácteos.

A composição do leite é diretamente afetada pela dieta e pela ação dos microrganismos ruminais, que atuam na degradação dos nutrientes do alimento ingerido. A função microbiana é fortemente influenciada pelo fornecimento de adequadas quantidades de energia e proteína [1] e a dieta deve suprir as necessidades da microbiota ruminal para o metabolismo protéico [5]. Tanto a eficiência de uso dos substratos oriundos da dieta como a fermentação microbiana sofrem interação com a fração degradável dos nutrientes no rúmen [8]. A produção de proteína microbiana e o aproveitamento da fração protéica não degradável podem ser maximizados pelo tipo e degradabilidade dos carboidratos fornecidos [1].

O objetivo deste trabalho é relatar uma situação de desequilíbrio nutricional, observada em uma propriedade da Bacia Leiteira Central Argentina, localizada na província de Córdoba, e as variações na composição do leite.

\section{MATERIAIS E MÉTODOS}

O trabalho foi desenvolvido em uma propriedade considerada modelo produtivo de uma das mais importantes bacias leiteiras da Argentina, a Bacia Leiteira Central, localizada na província de Córdoba. Nessa bacia leiteira habitualmente são fornecidos na dieta de vacas em lactação, como fonte de proteína e fibra: alfafa, aveia e centeio e como fonte de energia: grãos de milho e/ou sorgo, além da utilização de um subproduto da indústria leiteira, o permeado de lactose.

A unidade produtiva possuía um rebanho médio de 190 vacas em lactação, com produção de leite de 20L/vaca/dia. Os partos eram concentrados em março e abril, de forma a aproveitar os recursos forrageiros disponíveis. Os animais em produção eram divididos em dois lotes, conforme a média produtiva diária e o período da lactação, entretanto, a alimentação era baseada naqueles com maiores níveis produtivos. A dieta era composta por alfafa ad libitum sob pastoreio direto, grãos de milho e/ou sorgo, silagem de milho ou sorgo, feno de setária ou alfafa. As fêmeas gestantes e não lactantes eram transferidas ao grupo pré-parto trinta dias antes da parição prevista, onde recebiam feno de setária e silagem de sorgo e alfafa como alimentação. Desde 2005 a propriedade vinha sendo acompanhada por técnicos da cooperativa local e neste período foi introduzido o permeado industrial de lactose como fonte de carboidratos e energia, em substituição parcial aos grãos habitualmente usados, como milho e sorgo.

Em janeiro de 2006 foi observada a ocorrência de vacas em lactação com os seguintes sinais clínicos: claudicação, pododermatites, diarréia profusa e alimentos não digeridos nas fezes. Nas fêmeas puerperais os sinais clínicos eram agudos. Observouse também a diminuição dos sólidos totais (abaixo de $12,7 \%$ ), que estava ocorrendo desde novembro de 2005, e o aumento do teor de nitrogênio uréico no leite (NUL - acima de $17 \mathrm{mg} / \mathrm{dl}$ ). Os dados de composição do leite e produção mensais se encontram na Tabela 1.

\section{RESULTADOS}

O quadro observado sugeriu desequilíbrio nutricional, com suspeita de acidose ruminal, aguda e/ou crônica. Foram realizadas medidas de correção emergencial com a alteração da dieta de animais em produção (Tabela 2), de forma a diminuir a ingestão de carboidrato de alta degradabilidade e aumentar o aporte de fibra detergente neutra efetiva (FDNef) da dieta, visando com isto estimular a salivação e conseqüente o tamponamento ruminal.

Para isso foi indicado o repasse noturno pelos potreiros de alfafa, a mistura completa de feno e silagem e a diminuição da moagem da silagem fornecida aos animais visando aumentar o aporte de FDNef e reduzir os efeitos hierárquicos do rebanho. Também foi reduzida a quantidade de permeado de lactose na dieta. Ao grupo de vacas no período préparto foi adicionada à dieta uma pequena quantidade de permeado de lactose, a fim de promover adaptação 


\begin{tabular}{lcccccc}
\multicolumn{6}{l}{ Tabela 1. Composição e volume de leite produzido em uma propriedade na Bacia Leiteira Central da Argentina. } \\
\hline Mês & Litros & Gordura (\%) & Proteína (\%) & $\begin{array}{c}\text { Sólidos } \\
\text { Desengord. (\%) }\end{array}$ & $\begin{array}{c}\text { Sólidos } \\
\text { Totais (\%) }\end{array}$ & $\begin{array}{c}\text { Uréia } \\
\text { (mg/dl) }\end{array}$ \\
\hline Abr./05 & 121.808 & 3,95 & 3,36 & 8,86 & 12,81 & 19 \\
Maio/05 & 139.029 & 3,99 & 3,36 & 8,95 & 12,94 & 14 \\
Jun./05 & 141.008 & 3,90 & 3,33 & 8,95 & 12,85 & 23 \\
Jul./05 & 151.645 & 3,89 & 3,42 & 8,99 & 12,88 & 14 \\
Ago./05 & 153.313 & 3,83 & 3,45 & 9,01 & 12,84 & 11 \\
Set./05 & 153.537 & 3,81 & 3,38 & 9,00 & 12,81 & 14 \\
Out./05 & 154.380 & 3,78 & 3,38 & 8,94 & 12,72 & 15 \\
Nov./05 & 137.897 & 3,71 & 3,32 & 8,90 & 12,61 & 23 \\
Dez./05 & 121.444 & 3,78 & 3,33 & 8,90 & 12,68 & 19 \\
Jan./06 & 105.748 & 3,72 & 3,31 & 8,73 & 12,45 & 29 \\
\hline
\end{tabular}

\begin{tabular}{llcc} 
Tabela 2. Dieta das vacas em lactação, inicial (2005) e corrigida (2006). & \\
\hline \multicolumn{1}{c}{ Tipo } & \multicolumn{1}{c}{ Espécie } & \multicolumn{1}{c}{ Dieta Inicial } & Dieta Corrigida \\
\cline { 2 - 4 } & & Quantidade (vaca/dia) \\
\hline Forragem fresca & Alfafa & ad libitum & ad libitum \\
Forragem conservada & Feno Alfafa ou Setária & $03 \mathrm{~kg}$ & $04 \mathrm{~kg}$ \\
Grãos & Silagem Sorgo ou Milho & $10 \mathrm{~kg}$ & $13 \mathrm{~kg}$ \\
Concentrado energético & Permeado Lactose & $07 \mathrm{~kg}$ & $04 \mathrm{~kg}$ \\
Suplementação & Sorgo ou Milho & $18 \mathrm{~L}$ & $17 \mathrm{~L}$ \\
\hline
\end{tabular}

destas fêmeas à dieta direcionada aos animais em produção.

Foi observado no acompanhamento a campo que houve diminuição tanto na incidência quanto na intensidade dos quadros de acidose ruminal e das patologias podais. O escore corporal do rebanho sofreu leve melhora. Com relação à composição do leite houve diminuição do teor de uréia, sendo que em fevereiro de 2006 foram observados os seguintes resultados: $3,75 \%$ gordura, $3,33 \%$ proteína, $8,68 \%$ de sólidos desengordurados, $12,43 \%$ sólidos totais e $17 \mathrm{mg} / \mathrm{dl}$ de uréia. Nos meses posteriores foi observado um aumento do teor de sólidos totais do leite.

\section{DISCUSSÃO}

A deficiência de fibras pode ocasionar distúrbios ruminais semelhantes à acidose [3]. Assim, há inadequada mobilização dos aminoácidos e, conseqüentemente, diminuição na quantidade de proteína verdadeira e aumento no NUL. Estas frações protéicas auxiliam a avaliação do status protéico e energético de rebanhos leiteiros [2]. NUL acima de $17 \mathrm{mg} / \mathrm{dl}$ indica desequilíbrio nutricional, com excesso de proteína associado ao baixo aporte de carboidratos não estruturais [2].

Na situação descrita a dieta das vacas em lactação era baseada no consumo ad libitum de alfafa, uma leguminosa de elevada quantidade de proteína degradável no rúmen (PDR), e permeado de lactose. Leguminosas tendem a ter conteúdo de fibra detergente neutra (FDN) inferior a gramíneas, favorecendo a ingestão das primeiras [5]. Ainda, os carboidratos altamente fermentáveis como a lactose associados ao déficit de fibras levam à diminuição do $\mathrm{pH}$ ruminal, 
afetando assim a degradabilidade dos componentes da dieta, com efeito direto na taxa de crescimento dos microrganismos do rúmen [4].

O uso da proteína vegetal pela microbiota ruminal depende da quantidade de energia disponível, desta forma a concentração de amônia no líquido ruminal é conseqüência do equilíbrio entre produção e utilização pelos microrganismos e da absorção pela parede ruminal [6]. Apesar do elevado teor protéico da leguminosa, a degradabilidade da proteína da alfafa ocorre em velocidade inferior a da proteína de gramíneas [7]. Sendo assim, é possível que a falta de sincronismo de degradação entre as frações protéicas e de carboidratos da dieta [8] possam ter levado às alterações na composição do leite observadas.

A sincronia entre a digestibilidade de carboidratos e a degradabilidade no rúmen de proteínas torna mais adequada a utilização do nitrogênio pelos microrganismos ruminais [8].

Devido as diferentes taxas de degradação das proteínas é importante avaliar o suplemento energético utilizado. Grãos de milho, sorgo, cevada ou trigo, podem ser mais adequados às dietas com base alfafa que a lactose, ainda assim, o uso desta é mantido devido aos menores custos em relação aos demais, na região relatada.

Dessa forma, as medidas adotadas para correção da dieta possibilitaram a uma elevação do $\mathrm{pH}$ ruminal, através do aumento de FDNef, pelo maior tamanho de partículas da silagem, com redução do aporte de proteína degradável, pela restrição no consumo de alfafa e redução dos carboidratos altamente fermentáveis, pela diminuição do consumo de permeado de lactose. Com isso houve redução do quadro de acidose e melhoria na qualidade do leite produzido.

\section{CONCLUSÃO}

O desequilíbrio nutricional devido ao uso de carboidratos com rápida velocidade de degradação ruminal, associados ao baixo teor de fibras e a proteína de degradação mais lenta resulta em quadros de acidose com reflexos na saúde animal e na composição do leite produzido.

\section{REFERÊNCIAS}

1 Fregedolli F.L., Zeoula L.M., Prado I.N., Branco A.F., Caldas Neto S.F., Kassies M.P. \& Dalponte A.O. 2001. Efeito das fontes de amido e nitrogênio de diferentes digestibilidades ruminais. 1. Digestibilidades parcial e total. Revista Brasileira de Zootecnia. 30: 858-869.

2 Frosi R.A.M. \& Mülhbach P.R.F. 1999. Nitrogênio uréico no sangue (BUN) e nitrogênio uréico no leite (MUN) como ferramentas para monitorar o status protéico e energético da dieta de ruminantes. In: Tópicos em Produção Animal I. Porto Alegre: UFRGS, pp.41-54.

3 Gallardo M. \& Valtorta S. 2003. Factores nutricionales y ambientales que afectan la calidad composicional de la leche bajo condiciones de pastoreo. In: Taverna M. (Ed.) Manual de referencias técnicas para el logro de leche de calidad. 2 .ed. Rafaela: INTA, pp.103-118.

4 Hoover W.H. \& Strokes S.R. 1991. Balancing carbohydrates and proteins for optimum rumen microbial yield. Journal of Dairy Science. 74: 3630-3644.

5 Teixeira J.C. \& Teixeira L.F.A.C. 1998. Do alimento ao leite: Entendendo a função ruminal. Lavras: UFLA-FAEPE, 74p.

6 Moreira A.L., Pereira O.G., Garcia R., Filho S.C.V., Campos J.M.S., Souza V.G. \& Zervoudakis J.T. 2001. Produção de leite, consumo e digestibilidade aparente dos nutrientes, $\mathrm{pH}$ e concentração de amônia ruminal em vacas lactantes recebendo rações contendo silagem de milho e fenos de alfafa e de capim-coastcross. Revista Brasileira de Zootecnia. 30 (Suppl 1): 1089-2001.

7 Rassini J.B., Ferreira R.P., MoreiraA., Tupy O., Mendonça F.C. \& Bernardi A.C.C. 2003. Cultivo da alfafa - Características da leguminosa. Disponível em: <http://sistemasdeproducao.cnptia.embrapa.br/FontesHTML/Alfafa/SistemaProducaoAlfafa_2ed/ index.htm>. Acessado em 11/2007.

8 Van Soest, P.J. 1994. Nitrogen metabolism. In: Nutritional ecology of the ruminant. 2nd edn. Ithaca: Cornell University Press, pp. 290-311.

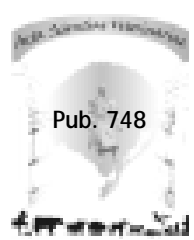

